\title{
Erratum to: Research on closed loop supply chain with reference price effect
}

\author{
Jie Xu • Nan Liu
}

Published online: 4 February 2015

(C) Springer Science+Business Media New York 2015

\section{Erratum to: J Intell Manuf DOI 10.1007/s10845-014-0961-0}

There are some calculation errors in the original publication of the paper, and Figs. 1-4, 9-14, 16 and 17 were published incorrectly. Therefore, the authors would like to make the following rectification:

1. The inaccurate Figs. 1-4 should be replaced with a table (Table 1). The reason is that the optimal performance for the M-, R-, and 3P-managed models is so close to each other numerically, and the subtle difference was not illustrated in the figures. However, Table 1 in this erratum shows the actual difference and is more helpful in understanding Corollaries 1-3.

2. Secondly, the more accurate Figs. 9, 10, 11, 12, 13, 14, 16 and 17 are displayed with this erratum $\left(r=30, c_{m}=20\right.$, $\left.c_{r}=10, A=5, B=1,000, \phi=100, \beta=0.5\right)$.
Table 1 The effect of reference price coefficient on the optimal performance in $M-, R$ - and $3 P$-managed channels, respectively

\begin{tabular}{|c|c|c|c|c|c|}
\hline & \multicolumn{5}{|c|}{ Reference price coefficient $(\delta)$} \\
\hline & 0.5 & 1 & 1.5 & 2 & 2.5 \\
\hline \multicolumn{6}{|c|}{ The retail price $\left(p^{*}\right)$} \\
\hline Model M & 91.10 & 69.84 & 59.21 & 52.83 & 48.57 \\
\hline Model R & 88.58 & 66.48 & 55.41 & 48.76 & 44.32 \\
\hline Model $3 P$ & 91.21 & 69.96 & 59.33 & 52.96 & 48.70 \\
\hline \multicolumn{6}{|c|}{ The collection rate $\left(\tau^{*}\right)$} \\
\hline Model M & 0.0596 & 0.0628 & 0.0660 & 0.0693 & 0.0726 \\
\hline Model R & 0.0597 & 0.0631 & 0.0665 & 0.0698 & 0.0732 \\
\hline Model $3 P$ & 0.0297 & 0.0313 & 0.0329 & 0.0345 & 0.0361 \\
\hline \multicolumn{6}{|c|}{ The profit of the manufacturer $\left(\Pi_{M}^{*}\right)$} \\
\hline Model M & 1,132 & 837 & 693 & 610 & 555 \\
\hline Model R & 1,135 & 841 & 697 & 614 & 562 \\
\hline Model $3 P$ & 1,130 & 835 & 691 & 607 & 554 \\
\hline \multicolumn{6}{|c|}{ The profit of the retailer $\left(\Pi_{R}^{*}\right)$} \\
\hline Model M & 569 & 421 & 349 & 307 & 281 \\
\hline Model R & 571 & 425 & 353 & 312 & 286 \\
\hline Model 3P & 566 & 419 & 347 & 305 & 278 \\
\hline
\end{tabular}

The online version of the original article can be found under doi:10.1007/s10845-014-0961-0.

J. Xu $\cdot$ N. Liu $(\varangle)$

Department of Management Science and Engineering,

School of Management, Zhejiang University, Hangzhou, China

e-mail: nliu@zju.edu.cn 


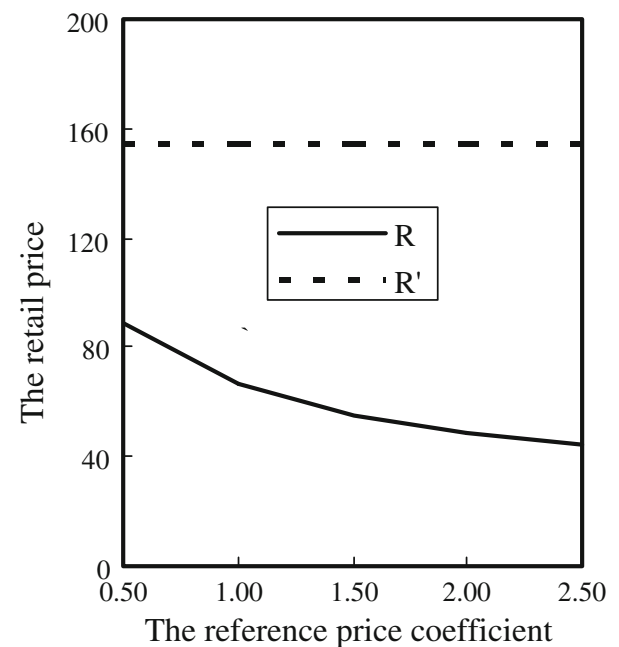

Fig. 9 The retail price $(R)$ with reference price effect versus $\left(R^{\prime}\right)$ without reference price effect in $R$-managed channel

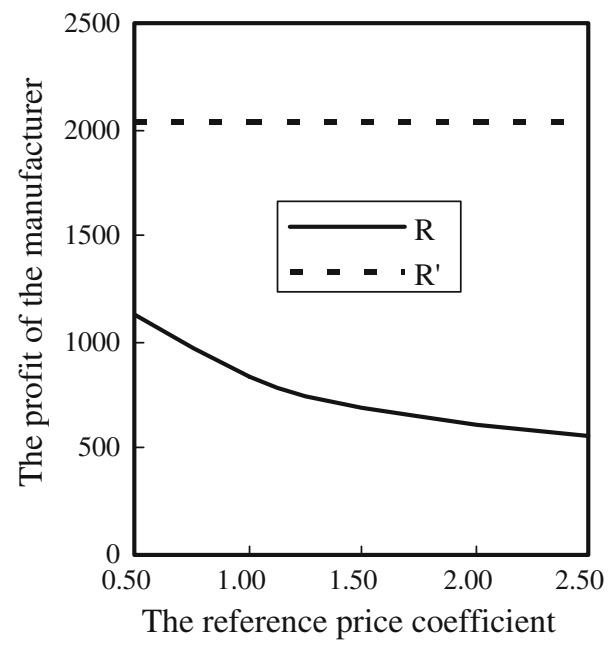

Fig. 10 The manufacturer's profit $(R)$ with reference price effect versus $\left(R^{\prime}\right)$ without reference price effect in $R$-managed channel

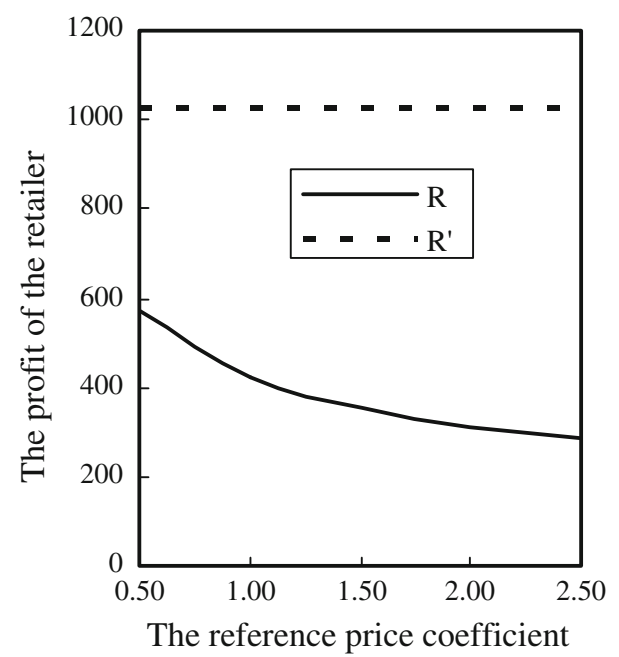

Fig. 11 The retailer's profit $(R)$ with reference price effect versus $\left(R^{\prime}\right)$ without reference price effect in $R$-managed channel

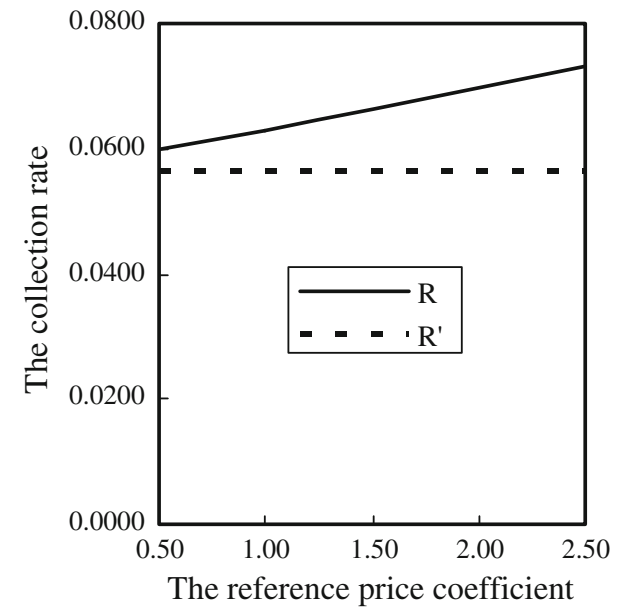

Fig. 12 The collection rate $(R)$ with reference price effect versus $\left(R^{\prime}\right)$ without reference price effect in $R$-managed channel

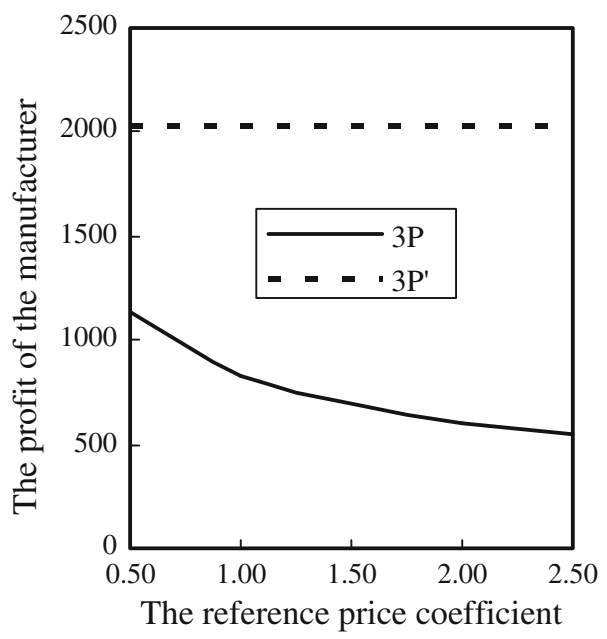

Fig. 13 The manufacturer's profit $(3 P)$ with reference price effect versus $\left(3 P^{\prime}\right)$ without reference price effect in $3 P$-managed channel

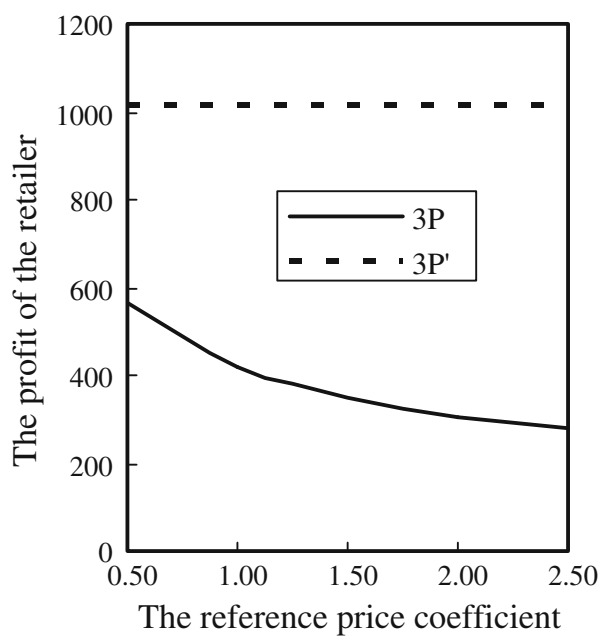

Fig. 14 The retailer's profit $(3 P)$ with reference price effect versus $\left(3 P^{\prime}\right)$ without reference price effect in $3 P$-managed channel 


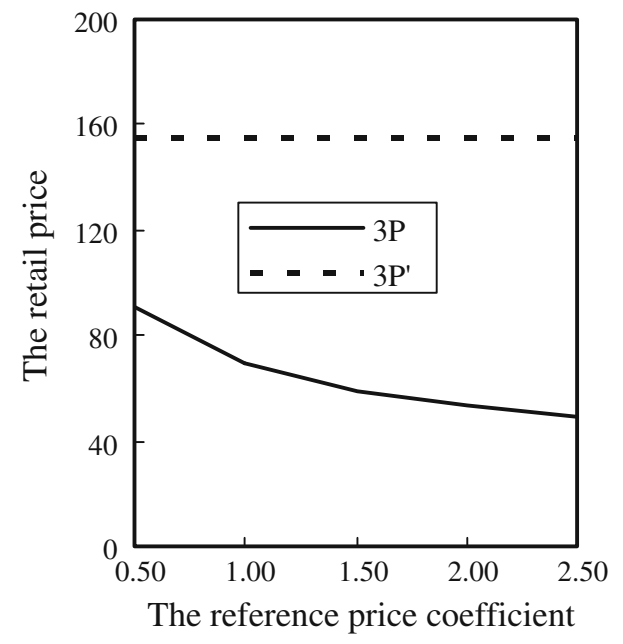

Fig. 16 The retail price $(3 P)$ with reference price effect versus $\left(3 P^{\prime}\right)$ without reference price effect in $3 P$-managed channel

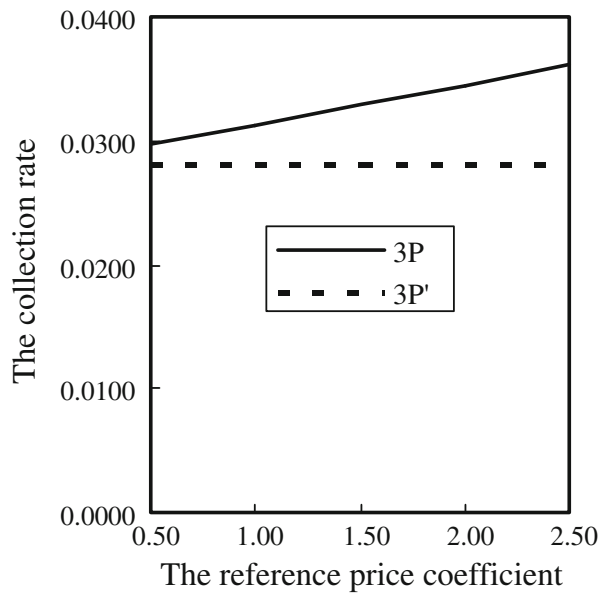

Fig. 17 The collection rate $(3 P)$ with reference price effect versus $\left(3 P^{\prime}\right)$ without reference price effect in $3 P$-managed channel 